Data de recebimento do artigo: $27-06-2017$

Data de aceite do artigo: $13-08-2018$

\title{
Uma breve análise do potencial da formação continuada como instrumento para o desenvolvimento das competências e habilidades requeridas pelo mercado de trabalho
}

\author{
Lacy de Aguilar \\ Graduada em Secretariado Executivo Trilíngue e em Pedagogia pela Universidade Federal de \\ Viçosa (UFV). E-mail: llamello@yahoo.com.br (Brasil) \\ Rosalia Beber de Souza \\ Doutora em Administração pela Universidade Federal de Lavras (UFLA). Professora efetiva \\ na Universidade Federal de Viçosa (UFV). E-mail: rosaliabeber@ufv.br (Brasil)
}

\section{Resumo}

Este artigo discute a importância da formação continuada para o desenvolvimento pleno das competências e habilidades de profissionais de Secretariado Executivo, requeridas pelo mercado de trabalho. Ao longo do texto é feita uma breve exposição teórica que abarca a atuação desse profissional no mercado de trabalho através dos tempos, destaca seu perfil, ideal e real, suas necessidades e motivações, além de dialogar com aspectos da valorização dada ao capital intelectual pelas empresas, atualmente. Procurou-se adotar uma metodologia de pesquisa que considerasse a complexidade, a variabilidade e a multiplicidade dos objetos, objetivos e problemas próprios das Ciências Humanas e do contexto sócio-organizacional. Para isto, foram utilizados questionários semiestruturados na análise dos dados, com os quais se buscou compreender a percepção e a importância dada por esses profissionais ao tema investigado Por fỉm, são apresentadas as discussões a partir das respostas obtidas junto ao universo abordado.

Palavras-Chave: Aperfeiçoamento. Motivação. Desenvolvimento de habilidades. Crescimento profissional. 


\title{
A brief analysis of the potential of continued education as an instrument for the development of competences and skills required by the labor market
}

\begin{abstract}
This article discusses the importance of continuing education for the full development of the competencies and abilities of the Executive Secretariat professionals required by the labor market. Throughout the text a brief theoretical exposition is made covering the work of this professional in the labor market through the time, highlighting their profile, ideal and real, with their needs and motivations, seeking to dialogue with aspects of the value given to the intellectual capital by companies, currently. The research sought to adopt a methodological bias that encompassed the complexity, variability and multiplicity of the objects, objectives and problems of the human sciences and the socio-organizational context. For this, semi-structured questionnaires were used and, in the analysis of the data, we sought to understand the perception and importance given by these professionals to the researched topic. The methodological aspects are also presented and the discussion is made based on the answers obtained with the universe addressed.
\end{abstract}

Keywords: Motivation. Professional growth. Skills development. Training.

\section{Como referenciar em APA:}

Aguilar, L. de, \& Souza, R. B. de (2019). Uma breve análise do potencial da formação continuada como instrumento para o desenvolvimento das competências e habilidades requeridas pelo mercado de trabalho. R.G.Secr.,GESEC, 10(1), 1-25.

\section{Como referenciar em ABNT:}

AGUILAR, L.; SOUZA, R. B. Uma breve análise do potencial da formação continuada como instrumento para o desenvolvimento das competências e habilidades requeridas pelo mercado de trabalho. R.G.Secr.,GESEC, São Paulo, v. 10, n. 1, p. 1-25, jan.-abr. 2019.
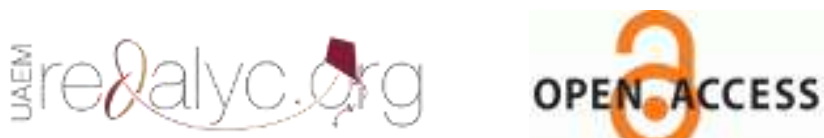


\section{Introdução}

As novas formas de organização da produção e do trabalho, impostas por um cenário de crescimento e de grandes mudanças que têm ocorrido na economia brasileira nos últimos anos, têm afetado a realidade de profissionais de todas as categorias.

Percebe-se que a crescente integração global das empresas vem provocando a multiplicação da oferta de produtos e de serviços, fomentando a tendência à internacionalização, demandando mudanças nas formas de concorrência e intensificando o uso das tecnologias digitais e incrementando constantes inovações tecnológicas e gerenciais.

Estas transformações demandam novas formas de atuação e alertam para a necessidade de incrementar e fortalecer as iniciativas de formação continuada e de desenvolvimento das competências individuais dos trabalhadores em todos os setores da economia.

No caso do profissional de Secretariado Executivo, esta questão também é premente, e as iniciativas no sentido de adequar-se a esta realidade também se fazem presentes, o que nos levou a refletir sobre a necessidade de prospectar o que tem sido feito, tanto de maneira particular como institucional, no sentido de promover sua atualização e capacitação.

A busca pelo entendimento destas premissas e por respostas a estes questionamentos levou ao desenvolvimento da pesquisa intitulada A importância da formação continuada para o desenvolvimento pleno das competências e habilidades requeridas pelo mercado de trabalho: o caso de egressos do curso Secretariado Executivo Trilíngue da Universidade Federal de Viçosa [UFV], que deu origem a este artigo e, cujo objetivo, foi identificar junto a estes profissionais, qual sua percepção a respeito da importância da formação continuada para o desenvolvimento e aperfeiçoamento de competências e habilidades requeridas pelo mercado de trabalho.

Para alcançar este objetivo foram contatados e selecionados os profissionais que estivessem engajados no mercado e tivessem efetivamente passado por algum processo de formação continuada. Em seguida foram aplicados questionários semiestruturados que foram respondidos pelos profissionais e analisados à luz do referencial teórico adotado a fim de compreender as atitudes e posturas dos indivíduos e das organizações nas quais atuam. Foram feitos questionamentos buscando compreender o que tem sido feito a esse respeito e de quem tem sido a iniciativa, se dos próprios profissionais ou das empresas. Pretendeu-se, também, 
compreender as motivações e demandas que fundamentavam essa atitude a fim de detectar se as organizações nas quais trabalham possuem uma política de valorização do capital humano que se apresente através do fomento à formação continuada.

\section{Referencial Teórico}

\subsection{O perfil do profissional de secretariado executivo}

Desde sua inserção nos escritórios, por volta de 1870, a função de secretariar sempre foi afetada pelas mudanças estruturais e administrativas pelas quais passaram as organizações ao longo dos anos. Inicialmente seu papel se limitava à execução de tarefas rotineiras e estritamente designadas pela chefia, sem espaço para a tomada de decisões, em ambientes de gestão com hierarquia rígida e estruturas organizacionais fragmentadas.

Com o passar dos anos, a atuação profissional foi se ampliando e o redesenho dos organogramas e das descrições dos cargos a partir da década de 1980 e 1990, permitiram uma atuação mais ativa e participativa, podendo o profissional tomar, para si, a responsabilidade por sua ascensão e pela participação nas decisões de futuro nas organizações, coordenando e gerindo equipes e projetos de trabalho que passaram a ser colocadas sob sua responsabilidade.

Atualmente, o profissional de secretariado executivo exerce um novo papel nas organizações publicas e privadas. De acordo com Wanser, (2010), “a profissão foi fortalecida significativamente a partir destes processos de adaptação à modernidade da regulamentação da profissão".

O profissional de Secretariado Executivo Trilíngue é essencialmente multifuncional e apresenta características que o tornam "capaz de atuar em diversas áreas de modo a suprir carências em todos os setores". (Breunig, s. d).

Para Sabino e Rocha (2004, p. 94) "a partir da evolução da profissão, foram-se delineando novos perfis de atuação: assessor, gestor, empreender e consultor".

De acordo com a descrição da profissão no site da UFV (2013), o profissional de Secretariado Executivo Trilíngue assume o "papel de staff dentro das corporações, gerenciando setores e pessoas, utilizando novas tecnologias, inovando, enfrentando mudanças culturais, econômicas, políticas e sociais com competência e discrição para diagnosticar e lidar com situações de conflitos". 
Desta forma, a partir da conjunção das abordagens demonstradas no presente estudo, podemos inferir que, através da atuação adjunta aos órgãos deliberativos, o profissional assume a função de assessor; ao aplicar as técnicas secretariais que auxiliam no desenvolvimento e implementação de trabalhos (organização, planejamento, controle e avaliação), assume o papel de gestor; apresenta-se como empreendedor na medida em que promove e implementa soluções que otimizem o trabalho, tanto no aspecto individual, quanto coletivo; e, é consultor, pela análise e entendimento da cultura organizacional, identificando pontos críticos e propondo estratégias de melhorias.

Medeiros e Hernandes (1999), afirmam que:

[...] a secretária assume o papel de assistente executiva ao assessorar seu superior, transmitindo-lhe informações e executando tarefas de confiança, dominando as habilidades requeridas e demonstrando capacidade para assumir responsabilidade sem supervisão direta, com autonomia para tomar decisões de acordo com os objetivos pré-determinados por seu superior executivo (Medeiros \& Hernandes, 1999, p. 72).

Estas afirmações nos permitem inferir que a atuação do profissional de secretariado, seja como gestor, empreendedor, consultor ou assessor, é permeada, principalmente, pela atuação no nível analítico-simbólico, aqui entendido com a capacidade de articular conhecimentos, competências e habilidades no sentido de desenvolver ações positivas no ambiente de trabalho.

Para Perrenoud e Magne (1999, p. 7), competência é "uma capacidade de agir eficazmente em um determinado tipo de situação, apoiada em conhecimentos, mas sem limitar-se a eles".

Percebe-se, assim, que a atuação do profissional de secretariado no nível analíticosimbólico deverá ser pautada por competências essenciais que incluem:

- Competência técnica na área de gestão: o que significa fazer uso e aplicação eficiente e eficaz de ferramentas, materiais, procedimentos, normas e sistemas corporativos com vistas a garantir o domínio e a aplicação de métodos secretariais e gerenciais;

- Competência comunicacional: buscar sempre o aprimoramento da comunicação com clientes internos e externos através da aplicação dos princípios e técnicas da boa comunicação oral e escrita, garantindo a qualidade da informação e promovendo a boa imagem da organização; 
- Competência social: saber promover a convivência harmoniosa, cultivando um clima de integração e de respeito às individualidades, no ambiente organizacional.

Isto significa dizer que é um profissional com atuação abrangente, que exerce sua função de maneira holística e integradora, apresentando habilidades para gerir, organizar e liderar. Sua atuação demanda competências que vão desde a tomada de decisão, até a realização de tarefas rotineiras, aliando competência técnica-operacional, competência comunicacional e social.

Atualmente o profissional de secretariado integra forças-tarefa e assume atribuições de acordo com a necessidade do projeto em questão. Wanser (2010) afirma que:

A ordem é agregar valor para a empresa da qual faz parte. [...], a secretária foi, é, e continuará sendo uma participante ativa no redimensionamento de seu papel profissional. Principalmente se levarmos em consideração que as organizações se mantêm em constante processo de reestruturação para lidar com as transformações do mercado [...]. (Wanser, 2010, p. 46).

A partir da leitura de Motta (2007), entendemos que o novo perfil do profissional de secretario compreende aprender a atuar como gerente, ciente da sua importância dentro da empresa. Por se verem obrigadas a acompanhar as mudanças e adequar o seu perfil às novas exigências, na busca por novos conhecimentos e aperfeiçoando suas habilidades, muitas Secretárias se tornaram gerentes, consultoras, coordenadoras e líderes de sucesso.

As organizações buscam atualmente profissionais proativos; capacitados; dinâmicos; competentes; com ousadia, maturidade e controle emocional para correr riscos calculados; que possuam visão global do negócio da organização e sejam capazes de antever problemas e apresentar soluções; e que, de posse de conhecimentos estratégicos, seja capaz de agregar valor à função que desempenha, colaborando para o sucesso da organização como um todo.

O profissional egresso do curso de Secretariado Executivo Trilíngue da UFV, mesmo considerando a alta qualidade de sua formação e todo o cabedal de conhecimentos que isso representa, será demandado, quando da aplicação destes conhecimentos, a buscar a formação continuada devido às constantes inovações e renovações pelas quais o mercado passa.

Assim, alcançar o diferencial na atuação profissional requer, necessariamente, participação em processos de atualização constante.

Wanser (2010) nos alerta para o fato de que:

[...] uma sólida formação acadêmica é necessária, porém não basta. [...] A falta de atualização tanto em relação à evolução tecnológica quanto em relação aos cursos, treinamentos, palestras, seminários e leituras - é uma forma de acomodação que pode prejudicar o processo de trabalho de 
toda a equipe, colocando em risco a empregabilidade do profissional e inviabilizando seu progresso na carreira. (Wanser, 2010, p. 60).

A formação continuada é uma realidade e reflete uma necessidade de o indivíduo estar sempre em conformidade com as inovações e o desenvolvimento de novas tecnologias e processos. É também, uma oportunidade para a aquisição e desenvolvimento de competências diversas que são fundamentais para um bom desempenho das atividades no ambiente de trabalho.

\subsection{A valorização do capital intelectual e motivação nas organizações}

Se considerarmos que uma organização é formada por pessoas e que os processos estão direta ou indiretamente ligados a elas, todo colaborador deve ser visto como elemento primordial para o funcionamento e para o alcance dos objetivos e metas das corporações. Para tanto, é de fundamental importância que exista uma política de valorização e reconhecimento dos recursos humanos e da importância dos colaboradores. É imprescindível, também, a motivação para o crescimento e a atualização, e os incentivos como um bom plano de cargos e salários, por exemplo, e ainda é preciso haver a implantação e fomento de processos formais de atualização e capacitação, dentro ou fora das organizações.

Nas corporações em que o colaborador é tido como patrimônio e tem seu capital intelectual valorizado, o treinamento é utilizado como uma forma de preparo técnico; de desenvolvimento pessoal e interpessoal; e, de qualificação profissional. Com esse alinhamento, a possibilidade de detecção de falhas, a medição do retorno em termos de lucratividade a partir do investimento em treinamento e capacitação e o desenvolvimento de estratégias que possibilitem a tomada de decisões, tornam-se mais latentes e facilitados.

Neste sentido, ações de valorização do capital humano fomentam as parcerias assertivas, motivadoras e estimulantes entre organizações e colaboradores, promovendo atuações orientadas para o sucesso e trazendo benefícios para todos.

Tomando como referência o pensamento de Chiavenato (2000), entendemos que a motivação se refere ao comportamento que é causado por necessidades dentro do indivíduo e que é dirigido ao alcance dos objetivos que irão satisfazer essas necessidades. Uma organização que não trabalha mecanismos de motivação e valorização de seus colaboradores, ou que não busque analisar ou entender os pontos de satisfação visando à manutenção dos 
mesmos na corporação, está fadada à chamada "erosão intelectual", na qual bons funcionários são perdidos para empresas concorrentes.

Se partirmos do princípio de que o colaborador é a alavanca principal que faz mover o empreendimento, as empresas e organizações não devem vê-lo como coadjuvante, e, sim, como personagem competidor, principal e indispensável em um cenário em que o objetivo é mostrar aos concorrentes que são capazes não só de criar, inovar e fazer a diferença. $\mathrm{O}$ incentivo ao treinamento, à capacitação e à qualificação permanente do quadro de funcionários deve ser assim, uma meta da empresa no sentido de reforçar e potencializar a aquisição e a atualização de competências de seus colaboradores.

Se levarmos em consideração o crescimento acelerado e a diversificação do mercado, bem como as novas oportunidades que são oferecidas para os profissionais melhor qualificados, pode-se ver a importância da formação continuada e da qualificação profissional permanente, tanto para o profissional, quanto para a organização.

\subsection{Formação Continuada}

Formação profissional continuada é toda a formação empreendida após a formação profissional inicial e após a entrada do indivíduo no mercado de trabalho, constituindo um fator determinante na empregabilidade e na potencialização do desenvolvimento pessoal e profissional dentro de uma organização.

De acordo com Galindo, Souza e Carvalho (2012, p. 1),

[...] a preparação e formação continuada do profissional tornaram-se elementos fundamentais, tanto para aumento da probabilidade individual de empregabilidade, quanto para o sucesso das organizações, na medida em que a educação permanente é entendida como estratégica básica de aquisição de competências. (Galindo, Souza \& Carvalho, 2012, p. 1).

Ao considerar que a formação do indivíduo é um processo de produção das capacidades necessárias ao exercício das atividades sociais e profissionais e, considerando, também, que a formação continuada é um requisito básico para a sobrevivência profissional e pessoal em um mercado cada vez mais competitivo, evidencia-se a importância da renovação e desenvolvimento constantes de conhecimentos, competências e atitudes, tendo em vista a valorização do capital humano dentro das empresas.

De acordo com o Departamento Intersindical de Estatística e Estudos Socioeconômicos [DIEESE] (2007): 
A Formação Profissional Continuada é associada a programas específicos de qualificação associada a uma ocupação e é destinada aos trabalhadores ocupados, podendo ser realizada internamente ou externamente às empresas. O conhecimento adquirido pode ser objeto de certificação realizada pela empresa ou por instituição pública ou privada. (DIEESE, 2007, p. 7).

Já Chiavenato (2003, p. 529), relaciona capacitação com o próprio desenvolvimento profissional, pois ela visa "ampliar, desenvolver e aperfeiçoar o ser humano para o seu crescimento pessoal e profissional e, também, para enfrentar positiva e assertivamente as mudanças estruturais e as inovações constantes por que passa o mercado".

Importante destacar que, de acordo com o DIEESE (2007), por formação continuada entende-se "toda aquela formação que promova a modificação do escopo de conhecimentos do trabalhador sobre os processos produtivos e de trabalho, ou que simplesmente represente uma atualização permitindo ao trabalhador adaptar-se a uma mudança pontual nestes processos".

No âmbito pessoal, o objetivo primordial da qualificação e da formação continuada é permitir ao indivíduo que desenvolva ou atualize os conhecimentos e competências já adquiridas durante sua formação inicial ou, ainda, permitir que ele possa adquirir novas competências no sentido de buscar uma promoção social e/ou econômica através de sua atualização profissional com vistas a uma inserção mais potencializada no mercado de trabalho.

Ao mesmo tempo, mudanças e turbulências exigem preparo, e o bom profissional nunca está pronto. Ele está em processo de construção e de renovação constantes, para isto, a formação continuada é mais do que necessária, é uma exigência do mercado de trabalho, pois ela permite a construção e renovação permanentes de competências, habilidades e atitudes que permitem o desenvolvimento do pensar, do querer e do fazer que, por sua vez, garantem a participação efetiva do profissional em cada etapa nos processos de mudança e no enfrentamento das turbulências.

Assim, a capacitação é uma oportunidade para o aperfeiçoamento do colaborador em sua função, não somente com vistas à melhor adaptação e produtividade na organização, como também para o desenvolvimento, o reconhecimento e a renovação do seu potencial de atuação, com consequente melhoria real na atuação e desempenho profissional.

Por outro lado, é crescente a necessidade de qualificação constante da força de trabalho, por parte das organizações, seja em razão de mudanças tecnológicas contínuas que afetam os processos produtivos em si, seja em decorrência das alterações introduzidas na 
própria organização administrativa do trabalho que, devido às inovações e avanços tecnológicos, passaram a demandar a reorganização de tarefas e atribuições exigindo uma elevação da qualificação do colaborador para o pleno desenvolvimento de suas funções.

Desta forma, para as organizações, a formação continuada se apresenta como uma demanda real e forte de renovação através da qualificação, desenvolvimento e fortalecimento de seu quadro funcional, o que irá se refletir em uma atuação mais incisiva no mercado.

A formação continuada pode ser implementada por meio de processos formais de aquisição de conhecimento mais estruturados - cursos de longa duração como pósgraduações-, ou por meio de cursos técnicos de maior abrangência e que implicam na modificação do escopo de conhecimento do trabalhador sobre os processos produtivos e de trabalho.

Schwartz (apud Ramos, 2001) propõe que a formação possui três dimensões: "conceitual, social e experimental". A primeira define-a como função do registro de conceitos teóricos e formalizados, estando associados aos títulos e diplomas. A segunda coloca-a no âmbito das relações sociais que se estabelecem entre conteúdos das atividades e classificações hierárquicas, sendo referente ao conjunto de regras e direitos relativos ao exercício profissional construído coletivamente. Por fim, a terceira dimensão está relacionada ao conteúdo real do trabalho, em que se inscrevem não somente os conceitos, mas o conjunto de saberes postos em jogo quando da realização do trabalho.

Porém, para efeitos deste estudo, o foco da formação continuada serão os treinamentos, por constituírem - devido a diversos fatores como custo, tempo de dedicação do colaborador e de sua abstenção da função - a modalidade mais comumente empregada no meio organizacional, modalidade esta que implica em atualizações pontuais, restritas à adaptação do colaborador a uma mudança qualquer nos processos desenvolvidos na organização.

Para Canabrava e Vieira (2006), treinamento é um:

[...] processo educacional, que é aplicado de maneira sistemática e organizada, no qual os aprendizes desenvolvem competências: conhecimentos, habilidades e atitudes, em função de objetivos definidos, sendo capazes de abordar e resolver uma situação mais complexa. (Canabrava \& Vieira, 2006, p. 72).

Para as autoras, o treinamento é uma oportunidade para a capacitação e o aperfeiçoamento do colaborador em sua função, com vistas à melhor adaptação e 
produtividade na organização. Já desenvolvimento envolve descoberta, reconhecimento e renovação do potencial de atuação, com consequente melhoria real no desempenho.

Para Boog (2001, p. 10), treinamento é “a ação sistematizada para a capacitação, o aperfeiçoamento e o desenvolvimento do indivíduo" e para Chiavenato (2003, p. 31) treinamento é o "processo educacional pelo qual as pessoas aprendem conhecimentos, atitudes e habilidades em função de objetivos definidos. Como objetivos definidos entendemse aquisição de conhecimentos e o desenvolvimento de atitudes, habilidades e competências para o exercício de uma função".

Fazendo uma releitura do pensamento de Boog (2001), percebe-se que quando os treinamentos são ofertados no formato tradicional no qual alguém assume a responsabilidade por oferecer um conhecimento pronto e acabado, de forma circunstancial e eventual, quase sempre não apresentam a eficácia desejada no processo de desenvolvimento das pessoas, posto que são assumidos como uma mera aquisição instrumental. Por consequência, essa ineficácia se apresenta, a médio e longo prazo, nos resultados observados nas organizações, demandando novos treinamentos ou corroborando com o mito de que treinamento é sinônimo de desperdício.

De outra forma, ainda de acordo com o pensamento de Boog (2001), quando os treinamentos são ofertados visando o desenvolvimento do capital intelectual humano, a partir de uma perspectiva integradora, aberta e participativa, envolvendo de forma interativa todos os atores do processo de ensino e aprendizagem, os resultados são mais positivos e assertivos, promovendo o desenvolvimento do colaborador de forma pessoal e profissional, melhorando, consequentemente sua performance de atuação na organização.

\section{Metodologia}

Para alcançar o objetivo da pesquisa, qual seja o de identificar junto aos profissionais de secretariado executivo trilíngue, egressos da UFV, qual sua percepção à respeito da importância da domação continuada para o desenvolvimento e aperfeiçoamento de competências e habilidades requeridas pelo mercado de trabalho, procurou-se adotar um procedimento metodológico que abarcasse a complexidade, a variabilidade e a multiplicidade 
dos objetos, objetivos e problemas próprios das Ciências Humanas e do contexto sócio organizacional.

Optou-se por realizar uma pesquisa que permitisse o uso de instrumentos e métodos flexíveis, que pudessem ser elaborados de forma a possibilitar a construção de uma compreensão interpretativa do fenômeno pesquisado à luz do referencial teórico e metodológico, adotados.

Foram, então, elaborados como instrumento de coleta de dados dois questionários: um semiestruturado, dirigido ao colaborador, com questões objetivas e subjetivas, e outro apenas com questões subjetivas, dirigido aos gestores.

O questionário do colaborador foi elaborado com dezessete perguntas, das quais nove eram objetivas, ou seja, tendo sim ou não como respostas; e, oito eram subjetivas e instigadoras, permitindo aos entrevistados emitirem suas opiniões e percepções acerca do tema pesquisado.

O questionário do gestor foi elaborado com oito questões subjetivas e instigadoras, de forma a provocar a expressão de suas opiniões e percepções a respeito do tema.

A aplicação se deu através de e-mail, devido à facilidade e agilidade tanto para a emissão quanto para a recepção das respostas.

A amostragem da pesquisa foi composta por profissionais egressos do curso Secretariado Executivo Trilíngue da UFV, do período de 2007 a 2012 e gestores empresariais aos quais os profissionais estivessem diretamente subordinados.

A amostra foi selecionada por acessibilidade ou conveniência, destituída de rigor estatístico e simplesmente admitida pelo pesquisador como representativa do universo que se pretende demonstrar, como nos ensina Moresi (2003):

A amostragem por acessibilidade ou conveniência apresenta-se como um tipo de amostragem não probabilística usual, destituída de qualquer rigor estatístico, na qual o pesquisador seleciona os elementos a que tem acesso, admitindo que estes possam representar o universo que se pretende analisar. (Moresi, 2003, p. 75).

Como características do grupo 1, egressos do curso de Secretariado Executivo Trilíngue da UFV de 2007 a 2012, destacamos: a) estar empregado na área ou em áreas conexas; b) ter participado de programas de formação continuada em qualquer modalidade.

Dentre os contatados que possuíam as características acima e concordaram em participar da pesquisa, obtivemos 8 (oito) participantes. 
A graduação em Secretariado Executivo Trilíngue da UFV permite o exercício de uma multiplicidade de funções nas mais diversas áreas organizacionais. Sendo que, no universo pesquisado foi percebida a atuação de $80 \%$ dos profissionais em áreas correlatas.

Desta forma, dentre os entrevistados encontramos secretários executivos em Universidades Federais, como assessores de gestão, tradutores, assistentes regionais, analistas supervisores, assistentes de importação, coordenadores de projetos, todos exercendo funções inerentes à formação como secretários executivos e atuando em organizações dos mais diversos ramos de atividades.

Como características do grupo 2, gestores empresariais, o pré-requisito era ter entre seus colaboradores, ao menos um egresso do curso Secretariado Executivo Trilíngue da UFV com o perfil apresentado acima.

Desta maneira, obtivemos três (3) participantes, quais sejam: uma Gerente Regional de uma empresa do Sistema $S$ (termo que define o conjunto de organizações das entidades corporativas voltadas para o treinamento profissional, assistência social, consultoria, pesquisa e assistência técnica), uma Gestora Educacional de um Instituto de promoção educacional, e uma Coordenadora Pedagógica de uma empresa de capacitação em nível nacional.

$\mathrm{Na}$ construção dos resultados, optou-se pela simples apresentação dos dados na forma de um quadro para efeito de melhor visualização dos percentuais. Em relação às respostas apresentadas às questões subjetivas, a sua compreensão baseou-se na perspectiva do paradigma interpretativo, próprio da pesquisa qualitativa e foram creditadas a partir do referencial teórico adotado.

Em virtude do sigilo, com relação aos participantes e às organizações nas quais trabalham, optou-se por identificar cada profissional utilizando, simplesmente, a referência à função que desempenham nestas organizações; portanto, serão identificados desta forma em suas falas aqui apresentadas. Os resultados, análise a discussão são apresentados a seguir.

\section{Análise e Discussão dos Resultados}

Esta seção apresenta os resultados obtidos com a pesquisa e sua análise à luz do referencial teórico adotado para o estudo. 
No Quadro 1, são apresentados os percentuais de respostas às perguntas objetivas. Esses dados serão analisados em comparação com as respostas às perguntas subjetivas ao longo da apresentação, análise e discussão.

O objetivo desta parte do questionário foi verificar as recorrências com relação à percepção dos entrevistados sobre alguns aspectos específicos, de modo a entender as unanimidades, como:

- se o profissional já passou por algum tipo de treinamento;

- se há a percepção individual sobre a valorização do capital humano pela empresa;

- se há programas de capacitação nas organizações onde trabalham;

- se há investimentos por parte das empresas no que se refere à formação continuada; e,

- se houve algum tipo de promoção de cargos desde que o colaborador começou a trabalhar na organização.

Estas informações foram utilizadas, também, para confrontar e ampliar o entendimento acerca de algumas das perguntas subjetivas, quando de sua análise.

Quadro 1 - Percentual de respostas às questões objetivas

\begin{tabular}{|c|c|c|}
\hline Questões & Sim & Não \\
\hline $\begin{array}{l}\text { Você passou por algum treinamento, curso ou capacitação desde que começou a trabalhar } \\
\text { nesta empresa? }\end{array}$ & $100 \%$ & \\
\hline Na sua percepção, sua empresa valoriza o capital intelectual? & $100 \%$ & \\
\hline $\begin{array}{l}\text { A empresa possui algum programa de capacitação e treinamento direcionado aos } \\
\text { colaboradores? }\end{array}$ & $75 \%$ & $25 \%$ \\
\hline $\begin{array}{l}\text { Há investimento financeiro em formação continuada (mesmo que a iniciativa seja } \\
\text { particular)? }\end{array}$ & $75 \%$ & $25 \%$ \\
\hline $\begin{array}{l}\text { Você, pessoalmente, acredita que, para a empresa, a formação continuada é necessária para } \\
\text { a melhoria da atuação do colaborador? }\end{array}$ & $75 \%$ & $25 \%$ \\
\hline $\begin{array}{l}\text { Em sua opinião, a formação continuada fomenta mudanças comportamentais e/ou } \\
\text { conceituais? }\end{array}$ & $100 \%$ & \\
\hline Você sente que estas iniciativas colaboram para um melhor desenvolvimento do trabalho? & $100 \%$ & \\
\hline $\begin{array}{l}\text { Você, pessoalmente, acredita que a formação continuada é importante para seu } \\
\text { desenvolvimento profissional? }\end{array}$ & $100 \%$ & \\
\hline Você foi promovido (a) desde que entrou na empresa? & $75 \%$ & $25 \%$ \\
\hline
\end{tabular}

Fonte: Elaborado pelas autoras.

A análise do quadro permite alcançar uma informação relevante: $25 \%$ dos colaboradores nunca foram promovidos desde que começaram a trabalhar nas empresas e, coincidentemente, são os mesmos que afirmaram que, para as empresas nas quais trabalham, a 
formação continuada não é necessária para a melhoria da atuação do colaborador. São os mesmos, também, que responderam negativamente a respeito de investimentos por parte da empresa em cursos e treinamentos e afirmaram que as mesmas não possuem programas ou políticas de formação continuada apesar de acreditarem que as empresas nas quais trabalham valorizam o capital intelectual.

Esta informação, quando confrontada com as respostas dos demais colaboradores (75\%), nos leva a inferir que o investimento em formação continuada permite o crescimento profissional e sua falta leva ao sentido oposto: estagnação, desmotivação e atraso.

Infere-se também, que há resistência das corporações, no sentido de entender, valorizar e fomentar iniciativas de aprimoramento constante dos seus colaboradores.

Com relação aos aspectos subjetivos levantados na pesquisa, optou-se por expor somente aquelas respostas que apresentassem maior significação tanto em termos de percepção do colaborador, quanto em termos de relevância para o presente estudo.

Esta análise se iniciará buscando compreender as opiniões dos participantes com relação à percepção da valorização do capital intelectual na organização.

Em resposta às perguntas objetivas, $25 \%$ dos entrevistados relatam que não há um programa de formação continuada nas empresas em que atuam. Porém, 75\% revelam a existência de algum tipo de fomento e incentivo à capacitação e ao desenvolvimento constante dos colaboradores, como pode ser visto em alguns relatos, a seguir:

Secretário Executivo (colaborador): Há retorno financeiro para aqueles que participam de ações de capacitação

Tradutor (colaborador): Eles dão suporte (financeiro) a cursos como inglês e outros, além de 'liberarem' para viagens para participação em cursos.

Gestora Educacional (gestor): Poucos são os cargos, poucas são as empresas que disponibilizam verbas para profissionais participarem de cursos abertos. Geralmente enviam uma pessoa para um curso quando se trata de temática bem específica.

Gerente Regional (gestor): Na empresa do sistema $S$, todos os empregados com mais de 01 (um) ano de contrato de trabalho, independente do nível e cargo, em pleno exercício de suas atividades, cujos contratos estejam efetivamente em curso podem fazer cursos que estejam ligados à área de trabalho e recebem bolsas de estudo para isto.

Verifica-se que, apesar de não apontarem para a existência de programas institucionais de formação continuada nas organizações onde trabalham os entrevistados evidenciam a contribuição financeira das empresas para esse tipo de atualização, o que serve como uma 
indicação de que, de certo modo, apoiam a aquisição de novos conhecimentos e de habilidades que podem trazer benefícios, tanto para o colaborador quanto para a empresa.

Para Chiavenato (2002, p. 529) há uma relação direta entre capacitação e desenvolvimento profissional individual, o que corrobora nossas inferências. Para ele, a capacitação "visa ampliar, desenvolver e aperfeiçoar o ser humano para o seu crescimento pessoal e profissional e, também, para enfrentar positiva e assertivamente as mudanças estruturais e as inovações constantes por que passa o mercado".

Quando se observa o percentual atingido pelas respostas à questão relativa à valorização do capital intelectual: $100 \%$ dos participantes afirmam perceber que há valorização do capital intelectual nas empresas em que atuam mesmo naquelas em que não há investimentos financeiros ou uma política de capacitação continuada.

Para efeitos de comprovação destas deduções, apresentamos, a seguir, alguns relatos de profissionais e gestores:

Gestora Educacional (gestor): As organizações que possuem políticas de formação continuada são as que reconhecem o valor dessa formação para a retenção de talentos e o alcance das metas corporativas. Nessas organizações, essa questão já faz parte da cultura corporativa; há um reconhecimento da importância da formação continuada.

Assessora de Gestão (colaborador): [...] temos auxílio no desenvolvimento, bolsa para ajudar a pagar cursos e, além disso, com frequência (a empresa) faz parcerias com escolas de idiomas e faculdades para que os colaboradores tenham descontos nos cursos. Há também uma pequena biblioteca na empresa, que possui livros e revistas de temas diversos e sobre assuntos mais focados em tecnologia e sempre que precisamos de algum livro/material novo, é bem fácil solicitar a compra.

Gerente Regional (gestor): No caso da nossa empresa (Sistema S) existe o Programa de Apoio à Graduação e Especialização - PROGE que se destina a concessão de bolsas de estudo para cursos técnicos (de pequena ou de grande duração); de graduação; especialização lato sensu, pós-graduação stricto sensu.

Analista Supervisor (colaborador): Ao longo do ano somos demandados a participar de cursos (internos e externos) de aperfeiçoamento. A empresa oferece cursos e treinamentos e financia cursos ou programas para os colaboradores diretos e treinamento e capacitação aos colaboradores terceirizados.

Assistente Regional (colaborador): Com o plano de cargos e salários da empresa, a instituição também paga parte dos estudos para quem quer se especializar.

Tomando como ponto de partida estas declarações, pode-se inferir que há uma preocupação com a constante atualização e desenvolvimento profissional dos colaboradores tanto da parte dos colaboradores individualmente, como também, das empresas, mesmo que não haja uma política de capacitação nas organizações. 
Retomando Boog (2001), infere-se que a valorização do capital humano é evidenciada quando a capacitação é feita a partir de uma perspectiva integradora, aberta e participativa, envolvendo de forma interativa todos os atores do processo de ensino e aprendizagem, os resultados são mais positivos e assertivos promovendo o desenvolvimento do colaborador de forma pessoal e profissional, melhorando, consequentemente, sua performance de atuação na organização.

Com relação aos investimentos em formação continuada, $25 \%$ dos participantes afirmam que as empresas em que trabalham não colaboram financeiramente.

Coincidentemente são estas as empresas que, apesar de valorizarem o capital intelectual, não apresentam programas de formação continuada e cujos colaboradores acreditam não haver uma percepção positiva, por parte das mesmas, com relação aos benefícios deste tipo de formação para a melhoria da atuação profissional de seus colaboradores. É interessante constatar, ainda que, nestas mesmas organizações os colaboradores não foram promovidos desde que iniciaram suas atividades.

No entanto, é importante frisar, que tanto os colaboradores quanto os gestores acreditam que, pessoalmente, a formação continuada é importante para seu desenvolvimento pessoal e profissional, tanto que participam de cursos de capacitação e treinamentos por iniciativa própria e com aporte financeiro particular, sem colaboração direta das empresas em que trabalham. Esta situação se revela nas palavras de alguns gestores e colaboradores:

Gestora Educacional (gestor): [...] algumas empresas possuem uma listagem de cursos e palestras que pretendem fazer para os funcionários por conta de uma demanda/necessidade imediata. Acabam sendo cursos 'soltos', que perdem seus efeitos em poucos dias após ministrados por não terem continuidade. Tal situação geralmente acontece em empresas sem uma política de retenção de talentos. Ainda tratam as pessoas como 'recursos' para fins imediatos. E ai a capacitação passa a ser algo oneroso, segundo a visão daquelas empresas.

Coordenadora Pedagógica (colaborador): Nas empresas que têm sua política de formação, ambas as situações são levadas em consideração: demandas advindas dos colaboradores e necessidades da empresa para dar conta dos objetivos corporativos. Agora, as empresas que só lidam com treinamentos esporádicos, a demanda é organizacional apenas. Eles pensam no imediato; não na formação do colaborador como ser humano integral.

Gerente Regional (gestor): As iniciativas partem dos próprios funcionários, que identificam a necessidade de aprimoramento e fazem a proposta de estudo para o responsável do setor. A alta direção da empresa, também tem identificado treinamentos importantes para a equipe gestora fazer em conjunto, e faz a convocação.

Assistente de Importação (colaborador): Eu acho que a importância depende muito se a formação é intimamente relacionada com o real trabalho que alguém desempenha na empresa. Caso não 
seja, pra [sic] mim não tem valor para a empresa, e sim para o funcionário, que poderá se aperfeiçoar e sair de lá.

Recepcionista Bilíngue (colaborador): Participei de cursos de capacitação sem ajuda da empresa. Acredito que têm influência porque acredito que toda experiência traz impactos significativos na vida da pessoa, tanto social quanto profissional.

Reportando ao referencial teórico, vemos que Wanser (2010) nos alerta para o fato de que o bom profissional alia seus interesses pessoais aos interesses da organização na qual trabalha. Desta forma, o colaborador que possui visão sistêmica da empresa na qual atua, saberá alinhar seu projeto de desenvolvimento pessoal e profissional às metas da organização, ampliando e valorizando sua postura profissional e colaborando para o crescimento e melhoria do ambiente de trabalho como um todo.

Perguntados sobre qual é a importância da formação continuada dos colaboradores, todos os participantes foram incisivos em afirmar que a formação continuada é fundamental. Eis alguns relatos:

Assistente Regional (colaborador): Mantém a pessoa atualizada e ajuda no desenvolvimento das habilidades. Assim, a pessoa pode se especializar na sua área de atuação.

Coordenadora de Projetos (colaborador): Há melhorias nos processos, ajustes de erros e buscas motivacionadas [sic] pelos estudos adicionais, além de colaborar no melhor desenvolvimento do trabalho.

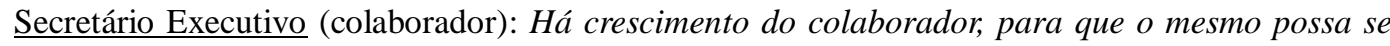
tornar mais produtivo particularmente e também em equipe.

Tradutor (colaborador): A importância está relacionada com o objetivo da capacitação e os motivos: se são particulares ou se por demanda da própria empresa.

No âmbito pessoal, o objetivo primordial da qualificação e da formação continuada é de permitir ao indivíduo que desenvolva ou atualize os conhecimentos e competências já adquiridas durante sua formação inicial ou, ainda, permitir que ele possa adquirir novas competências no sentido de buscar uma promoção social e/ou econômica através de sua atualização profissional com vistas a uma inserção mais potencializada no mercado de trabalho.

Com relação aos propósitos da empresa ao investir na capacitação, cada participante levantou uma questão específica, como democratização e oportunidades, aumento do status da empresa e evolução profissional ou o simples atendimento a necessidades coorporativas imediatas, como pode ser visto nos relatos a seguir:

Analista Supervisor (colaborador): A empresa aposta na formação para manter seus colaboradores atualizados e para democratizar as oportunidades dentro da própria empresa, já 
que há um plano de cargos e salários e para que os colaboradores possam atender satisfatoriamente as necessidades da empresa.

Coordenadora de Projetos (colaborador): Acredito ser essencial também, pois uma empresa com colaboradores que não se atualizam e sem condições de acompanhar as novas tendências, não evolui.

Assistente Regional (colaborador): Manter o padrão de qualidade exigido pela empresa e buscar o aperfeiçoamento do profissional.

Gestora Educacional (gestor): As organizações podem ser divididas em duas categorias: aquelas que têm políticas de formação continuada e aquelas que formatam uma listagem/rol de cursos/palestras/seminários (eventos em geral) a serem ministrados durante o ano baseados em demandas e necessidades imediatas, diante dos objetivos que querem alcançar em curto prazo.

Podemos relacionar essas informações com a necessidade de adequação profissional às tendências atuais em termos de inovação, desenvolvimento tecnológico e mesmo de atuação profissional no mercado, de modo a manter ou elevar o padrão de qualidade das empresas. É uma exigência do mercado que o profissional esteja preparado e atualizado para enfrentar os desafios que surgem a cada dia.

Wanser (2010), afirma que, ao buscar a capacitação o bom profissional "agrega valor para a empresa da qual faz parte. [...] Principalmente se levarmos em consideração que as organizações se mantêm em constante processo de reestruturação para lidar com as transformações do mercado [...]”, ou seja, o profissional que se mantém atualizado está mais bem preparado para se adequar à natureza mutante das empresas.

Com relação aos benefícios que podem ser alcançados com a formação continuada, os participantes foram enfáticos em afirmar que os maiores benefícios são prazer pessoal pela possibilidade de alcançar novos conhecimentos, motivação para enfrentar novas possibilidades, oportunidades e tarefas, a possibilidade de melhorias no salário e enriquecimento do currículo. Como pode ser visto nos relatos a seguir:

Recepcionista Bilíngue (colaborador): Além de prazer pessoal, que, em minha opinião, é o primeiro, novas possibilidades de atuação, ser um profissional procurado pelo mercado $e$ aumentos salariais.

Secretário Executivo (colaborador): $O$ principal benefício é com relação ao crescimento pessoal e profissional, já que pode se tornar mais produtivo na execução de seu trabalho, particularmente e também em equipe.

Assistente de Importação (colaborador): Dependendo da empresa, pode permitir buscar uma remuneração melhor; apresentar mais competitividade, no caso de estar concorrendo a uma vaga.

Assistente Regional (colaborador): O profissional é mais bem preparado e, consequentemente, mais motivado, buscando inovar e agregar valores e conhecimento. 
Com isso, percebe-se que, buscar o diferencial na atuação profissional passa por buscar a atualização constante.

De acordo com Wanser (2010),

[...] uma sólida formação acadêmica é necessária, porém não basta. [...] A falta de atualização tanto em relação à evolução tecnológica quanto em relação aos cursos, treinamentos, palestras, seminários e leituras - é uma forma de acomodação que pode prejudicar o processo de trabalho de toda a equipe, colocando em risco a empregabilidade do profissional e inviabilizando seu progresso na carreira. (Wanser, 2010, p. 60).

Da mesma forma, Chiavenato (2000, p. 117), pondera que "a motivação se refere ao comportamento que é causado por necessidades dentro do indivíduo e que é dirigido a alcance dos objetivos que irão satisfazer essas necessidades".

Isso leva a enfatizar que as organizações, que não se preocupam em motivar ou valorizar seus colaboradores, ou que não analisam ou entendem os pontos de satisfação visando ao desenvolvimento das qualidades e habilidades dos profissionais que se encontram à sua disposição, estão fadadas à chamada: “erosão intelectual” através da qual, bons profissionais são perdidos para outras organizações.

Quando questionados a respeito das mudanças comportamentais ou conceituais provocadas ao participar de algum processo de formação continuada, estas mudanças foram avaliadas de maneira positiva pelos participantes, como pode ser visto nas respostas apresentadas:

Assessora de Gestão (colaborador): Se abrir para novos conhecimentos nos possibilita a evolução profissional e pessoal também. Quanto mais percebemos o quanto há ainda para aprender, podemos identificar os esforços que precisam ser feitos e quanto mais domínio temos de um assunto, mais confiança desenvolveremos também.

Coordenadora de Projetos (colaborador): nova visão de um processo de trabalho ou nova forma de executá-lo, bem como promover melhor percepção das relações de trabalho com colegas $e$ superiores.

Secretário Executivo (colaborador): todas as experiências trazem algum tipo de mudança. No meu caso, essas mudanças se refletiram na qualidade do meu trabalho.

A capacitação através dos processos de formação continuada é como apresentada anteriormente uma oportunidade para o aperfeiçoamento do colaborador em sua função, não somente com vistas à melhor adaptação e produtividade na organização, como também para o desenvolvimento, o reconhecimento e a renovação do seu potencial de atuação, com consequente melhoria real na atuação e desempenho profissional. 
Com relação aos efeitos dos treinamentos, cursos e capacitações na realização do trabalho ou no desempenho das funções, as respostas remeteram, em sua grande maioria, à melhoria da qualidade do trabalho executado, ao crescimento do colaborador e a segurança e eficiência na execução de tarefas, conforme respostas apresentadas:

Assessora de Gestão (colaborador): Os efeitos estão relacionados à qualidade do trabalho, em ter mais segurança do que é feito e, também, ter um olhar mais crítico sobre o que é bom e o que precisa ser melhorado na área.

Secretário Executivo (colaborador): Os efeitos aparecem no crescimento do colaborador, para que o mesmo possa se tornar mais produtivo, eficiente e seguro na execução de uma tarefa particular ou em grupos de trabalho.

Tradutor (colaborador): Melhora a eficiência, pois o sujeito estará apto a desenvolver sua tarefa da melhor maneira possível.

Analista Supervisor (colaborador): Rever a forma como se executa o trabalho e a trazer melhorias e desenvolvimento de novas atitudes.

Retomando Chiavenato (2002), pode-se estabelecer relação entre capacitação e desenvolvimento profissional, tendo em vista que o aperfeiçoamento do indivíduo através do crescimento pessoal e profissional o prepara para enfrentar com competência, eficiência e eficácia as alterações estruturais e as inovações constantes que se apresentam no mundo corporativo.

É crescente a necessidade de qualificação constante da força de trabalho, seja em razão de mudanças tecnológicas contínuas que afetam os processos produtivos em si e demandam a reorganização de tarefas e atribuições, seja pelas exigências do mercado que, cada vez mais competitivo, acaba por alimentar o ciclo que contribui para a elevação da qualificação profissional.

No entanto, é importante considerar que a capacitação, para apresentar resultados em termos de eficiência e eficácia, deverá surgir do alinhamento entre as necessidades de desenvolvimento profissional individual e as metas e projetos da organização.

De outra forma, se os treinamentos são ofertados com objetivos puramente operacionais, como mera aquisição instrumental, no sentido de atendimento de demandas imediatas, circunstanciais e eventuais da organização, dificilmente a eficácia desejada no processo de desenvolvimento das pessoas será alcançada. Essa ineficácia se apresentará a médio e longo prazo nos resultados observados nas organizações demandando retrabalho, ou 
seja, novos treinamentos. E, ainda, pode contribuir para corroborar o mito no qual se crê que treinamento é sinônimo de desperdício.

\section{Considerações Finais}

Os estudos sobre esta temática se tornam relevantes na medida em que desnudam fatores que inibem ações de formação continuada ou na medida em que dão relevo àqueles fatores que contribuem para subsidiar sua promoção. Ao mesmo tempo, são igualmente importantes por apresentar novas perspectivas, contribuindo para a implementação de políticas e programas de formação continuada e, também, subsidiando e fomentando processo de valorização do capital intelectual nas organizações.

Os dados alcançados refletem uma forte tendência dos profissionais no sentido de buscar o aperfeiçoamento constante.

Em termos de compreensão da importância da formação continuada, fica evidente que tanto colaboradores quanto gestores organizacionais estão engajados em fortalecer e fomentar esta busca de aprimoramento, visando tanto o crescimento do profissional de forma individual, quanto da organização através da atuação calcada na apreensão - por meio de treinamentos e cursos de capacitação - das inovações e renovações que se apresentam constantemente no mercado.

Verificou-se que, tanto o gestor quanto o colaborador, têm uma visão muito particular sobre o tema e ambos têm importantes colaborações a dar no sentido de elucidar a importância da formação continuada no desenvolvimento da carreira profissional.

Ao realizar este estudo, foi possível perceber que o incentivo ao treinamento, à capacitação e à qualificação permanente do quadro de colaboradores deve ser uma meta das organizações não somente no sentido de reforçar e potencializar a aquisição e a atualização de competências, como também de mantê-los afinados com os objetivos da empresa.

A partir dos resultados alcançados, é possível perceber que a demanda por formação continuada é latente e reflete uma necessidade de o profissional de estar sempre alinhado com as inovações e o desenvolvimento de novas tecnologias e processos, de modo a adquirir e desenvolver competências que serão fundamentais para o desenvolvimento do trabalho na empresa. 
Desta forma, pode-se depreender que os estudos sobre esta temática se tornam relevantes na medida em que desnudam fatores que inibem ações de formação continuada ou na medida em que dão relevo àqueles fatores que contribuem para subsidiar sua promoção. Ao mesmo tempo, são igualmente importantes por apresentar novas perspectivas, contribuindo para a implementação de políticas e programas de formação continuada, e, também, subsidiando e fomentando processo de valorização do capital intelectual nas organizações.

No entanto, é importante considerar que a capacitação, para apresentar resultados em termos de eficiência e eficácia, deverá surgir do alinhamento entre as necessidades de desenvolvimento profissional individual e as metas e projetos da organização. Dessa forma, é importante que as organizações entendam a necessidade de adequação de seus colaboradores às tendências atuais em termos de inovação, desenvolvimento tecnológico e mesmo de atuação profissional no mercado.

As organizações são formadas por pessoas e tanto os processos e inovações quanto sua sustentação e longevidade estão ligadas, direta ou indiretamente, a elas. Por isso, é preciso fomentar em sua cultura o reconhecimento da importância do capital humano.

As organizações que compreendem que cada colaborador deve ser visto como elemento primordial para seu bom funcionamento e para o alcance de seus objetivos e metas também assumem que é de fundamental importância a implantação de uma política de valorização e reconhecimento dos recursos humanos e do seu capital intelectual. Isso porque as organizações que não trabalham mecanismos de valorização e capacitação de seus colaboradores ou que não buscam analisar ou entender os pontos de satisfação visando à manutenção dos mesmos estão fadadas à chamada: erosão intelectual, na qual bons funcionários são perdidos para empresas concorrentes.

Por fim, ressaltamos que este trabalho não teve a pretensão de esgotar o tema. É preciso e necessário que sejam realizados novos estudos, com maior aprofundamento, principalmente nas questões que se apresentam como inibidores do processo de formação continuada, como, por exemplo, a resistência das corporações no sentido de entender, valorizar e fomentar iniciativas de aprimoramento constante de seus colaboradores. 


\section{Referências}

Boog, G. G. (Coord.). (2001). Manual de Treinamento e Desenvolvimento: um guia de operações - manual oficial da ABTD. São Paulo: Makron Books.

Breunig, J. (s. d). Especialista e multifuncional. Recuperado em 08 de julho, 2014, de < http://www.institutokenntnis.com.br/?page=artigos\&a=2>

Canabrava, T., \& Vieira, O. de F. A. (2006). Treinamento e desenvolvimento para empresas que aprendem. Brasília: SENAC/DF.

Chiavenato, I. (2000). Gestão de pessoas: o novo papel dos recursos humanos nas organizações. Rio de Janeiro: Campus.

Chiavenato, I. (2003). Introdução à teoria geral da administração (6a ed.). Editora Campus: Rio de Janeiro.

DIEESE. (2007). Formação profissional continuada nas empresas: diretrizes para pesquisa. Convênio TEM/DIEESE. Recuperado em 14 de fevereiro, 2014, de <www.portal.mte.gov.br/data/files/.../sumario_2009_TEXTOV9.pdf>

Fiorese, R. (2003). Metodologia da pesquisa: como planejar, executar e escrever um trabalho científico. João Pessoa: EDU.

Galindo, A. G., Souza, E. C. P., \& Carvalho, I. C. (2012). Competências declaradas para atuação do profissional de secretariado executivo sob a perspectiva dos acadêmicos da Universidade Federal do Amapá - UNIFAP. Recuperada em 07 de julho, 2014, de http://www.fenassec.com.br/xviii_consec_2012/1_lugar_artigo_competencias_declara das.pdf.

Medeiros, J. B., \& Hernandes, S. (2006). Manual da secretária (10a ed.). São Paulo: Atlas

Moresi, E. (Org). (2003). Metodologia de pesquisa. Brasília: UCB.

Motta, P. R. (2007). Gestão contemporânea: a ciência e a arte de ser dirigente (16a ed.). Rio de Janeiro: Record.

Perrenoud, P., \& Magne, B. C. (1999). Construir: as competências desde a escola. Porto Alegre: Artmed.

Ramos, M. N. (2001). A pedagogia das competências: autonomia ou adaptação? São Paulo: Cortez.

Sabino, R. F., \& Rocha, F. G. (2004). Secretariado: do escriba ao web writer. Rio de Janeiro: Brasport. 
Universidade Federal de Viçosa. (2013). Secretariado Executivo Trilíngue: o curso: profissão. $\begin{array}{lllll}\text { Recuperada } & \text { em } & 19 & \text { de } & \text { novembro, }\end{array}$ <http://www.secretariadoexecutivo.ufv.br/?area=profissao>.

Wanser, E. (2010). A Secretária que faz: vivências e convivências. Blumenau: Nova Letra. 